CHAPTER 9

\section{Primitively rational belief-forming processes}

Ralph Wedgwood

One approach to understanding 'reasons' - including both reasons for action and reasons for belief - postulates a fundamental connection between reasons and reasoning. According to this approach, there is a reason for you to $\varphi$ - where $\varphi$-ing could be either an action (such as writing $a$ letter) or an attitude (such as believing that it is snowing) - if and only if there is a possible process of sound or rational reasoning that could take you from your current state of mind to your rationally $\varphi$-ing.

This approach is familiar in discussions of reasons for action. As Bernard Williams (I995: 35) put it, for there to be a reason for you to $\varphi$, there must be a 'sound deliberative route' that leads from your current state of mind to your being motivated to $\varphi$. Presumably, Williams's reference to 'a sound deliberative route' comes to more or less the same thing as my own terminology of a 'possible process of rational reasoning.'

It is clearly possible to take the same approach to understanding reasons for belief. You have a reason to believe $p$ if and only if there is some possible process of rational reasoning that could lead you from your current state of mind to your being rationally inclined to believe $p$. So one way to make progress in understanding reasons for belief is to investigate which processes of reasoning count as rational.

In this chapter, I shall investigate this notion of rational processes of reasoning. Specifically, I shall focus here on belief-forming processes - that is, types of mental process that result in the thinker's forming a belief in some proposition. A full theory would also have to consider other processes as well - such as processes that result in the thinker's revising her beliefs in various ways. But for simplicity, I shall focus exclusively on belief-forming

Admittedly, there are other approaches to understanding reasons - such as the approach of John Broome (2004). But for my purposes, it is enough if there is at least one concept expressed by the term 'reasorn' that is to be undersrood along the lines of his appronch. (It does not ma purposes if there are also other concepts that can be expressed by the term 'reason', processes here. I shall try to solve a basic problem that arises when we try to understand how belief-forming processes can be rational.

\section{I HOW CAN THERE BE FALLIBLE PRIMITIVELY} RATIONAL PROCESSES?

The problem that I shall try to solve concerns belief-forming processes that have the following three properties:

a. They are rational processes, and the beliefs that we form through these processes are themselves rational or justified beliefs.

b. Even if in most cases these processes reliably lead to correct beliefs (that is, beliefs in true propositions), they are not infallible: it is still logically possible for beliefs that are formed through these processes to be incorrect (that is, to be beliefs in false propositions).

c. The rarionality of these processes is basic or primitive. That is, the rationality of these processes is not due simply to the availability, purely by means of some other rational processes, of a rational or justified belief in the reliability of these processes. As we might put it, the rationality of these processes is not due to the availability of a 'process-independent justification' for these processes.

In this chapter, I shall focus on a specific example of a belief-forming process that has these three properties - what I shall call the process of 'taking experience at face value'.

Very roughly, the process of taking experience ar face value is the process whereby one comes to believe a proposition $p$ in response to the fact of one's having a conscious experience that has $p$ as part of its representational content. For example, if my present experience has the proposition 'I am holding my hands in front of my face' as part of its content, then this process would involve my responding to this experience by forming the belief that I am indeed holding my hands in front of my face.

This initial specification of the process is obviously too rough. I could have an experience of this kind even if it also appeared to me that a demon was talking to me out of the palm of my hand, mocking me with the claim that all of my experiences are complete illusions. In this case, it would clearly not be rational for me to form the belief that I really am holding my hands in front of my face. If this process of taking sensory experience at face value' is to be rational, it is not sufficient for forming a belief by means of this process that one just forms a belief in $p$ in response to any experience that has $p$ as part of its content. It must also be the case that one's experiences, background beliefs, and other mental states do not contain 
any special defeating reasons of this kind. So a more precise name for this process would be the 'process of taking one's experiences at face value, when such special defeating reasons are absent'. ${ }^{2}$ But for the most part, I shall omit this qualification here.

Even with this qualification, however, this is still only a rough description of the process of taking experience at face value. First, this description says nothing about the fact that even when a proposition $p$ is part of the representational content of one's experience, the degree of belief that one may place in $p$ through taking one's experience at face value can vary enormously, depending on how specific this proposition $p$ is. The proposition that there are exactly 26 lights arranged in a circle in front of one's eyes may be part of the representational content of one's experience; but without careful counting, one should presumably place a much lower degree of belief in this proposition than in the weaker and less specific proposition that there are some lights before one's eyes.

Secondly, this description of the process of taking one's experience at face value may also require revision if it is true, as many philosophers have argued, ${ }^{3}$ that the primary representational content of sensory experience is non-conceptual. However, even if this is true, we could still make sense of what we might call the 'conceptualized upshot' of experience, which would be the result of one's conceptual capacities' operating on the primary nonconceptual content of experience. Then we could refine our description of the process of taking one's experience at face value by saying that it involves forming the belief in a proposition $p$ in response to having an experience that has $p$ as part of its 'conceptualized upshot'. In general, it will clearly be a difficult and controversial matter to give a fully precise account of the process of taking experience at face value. I believe, however, that the rough description that I have given will be sufficient for present purposes.

It is important, however, that as I have characterized it, this process of taking one's experiences at face value need not involve relying on any antecedent belief in the reliability of one's experiences (or indeed on any belief about one's experiences at all). This process involves coming to believe $p$ in direct response to having an experience that has $p$ as part of irs representational content (together with the absence of defeating reasons of

In his comments on this essay, Stephen Schiffer argued that my reference to the absence of specia defcaters... stands in for something extremely complicated'. But in fact, it docs not 'stand in for' defeaters... stands in for something extremely complicated. But in fact, it does not stand in for
anything. We have a general notion of a defeater - that is, the general notion of a set of mental states

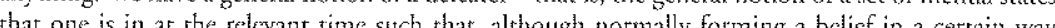

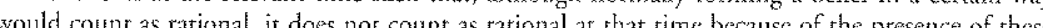
ment sures is this For a Burge (2003); for the other side of the debate, see McDowell (1994b). the relevant sort); it is not required that one should have any belief about one's experiences.

It seems plausible that this process has the three properties that I listed above. First, it seems rational to form beliefs by means of this process as I shall sometimes say, it is rational to 'engage in' this process. Since $m$ current experiences, background beliefs, and other mental states contain no special defeating reasons of the relevant kind (I do not seem to see any demon talking to me out of the palm of my hand or the like), it is rational for me now to form the belief that I am holding my hands in front of $m y$ face; and the belief that I form in this way is itself a rational or justified belief.

Secondly, this is obviously a fallible process. If I really were being undetectably deceived by an evil demon, then the overwhelming majority of the beliefs that I would form by means of this process would be false, and so in this case, this process would fail to be a reliable guide to the truth.

Thirdly, it also seems plausible that this process is 'primitively' rational. It does not seem plausible that the rationality of this process is explained merely by the availability of any process-independent justification for the process. ${ }^{4}$ Admittedly, it is not as obviously true that this process has this third property as that it has the first two properties that I listed above. But in this chapter, I shall simply assume that this process has these three properties, without making any attempt to justify this assumption. I am invoking these assumptions in order to illustrate a more general problem. If these three assumptions are not in fact true of the process of taking experience at face value, I would only need to pick another process that does satisfy these three assumptions; and it seems indisputable that there are at least some processes of this kind.

Now the idea of such primicively rational belief-forming processes seems to give rise to a problem. How can a belief-forming process (i) be rational, given that (ii) the process is fallible and might fail to be leading us to the truth, and (iii) it is not rational in virtue of the availability of any process-independent justification of the process?

The problem seems to arise from the following point: it seems that if a belief-forming process is rational, then forming beliefs by means of the process must be a reasonable way to pursue the truth - that is, to pursue the

My claim that the process of taking one's sensory experiences ar face value is primitivcly rational is similar in sprit to the position that James Pryor (2000) has called 'dogmatisn'. My claim agrees with Pryor's 'dogmatist' that the rationality of taking your sensory experience at face value is not explained by auy justification that you have for believing in the reliability of your experiences. However, although I agree with this dogmatist on this point, I do not agree with another thesis that many dogmatisss endorse - the thesis that the rationality of this process does not even entail the availability 
goal of believing the proposition in question if and only if that proposition is true. But if a process is perfectly capable, in some possible circumstances, of leading one to believe falsehoods rather than truths, then how could the process be a reasonable way for one to pursue the truth, unless one has some process-independent reason for regarding the process as reliable in one's actual circumstances?5

This account of the problem points in the direction where we must look to find a solution. In effect, the solution would involve (a) giving a more precise clarification of the intuitive formulation that I have just used - a 'reasonable way for one to pursue the truth' - and (b) explaining how the process of taking experiences at face value really does satisfy this formulation when it is clarified in this more precise way.

An ambitious version of such a solution would be in a sense reductive: that is, it would clarify this intuitive formulation by analysing what it is for something to be 'a reasonable way for one to pursue the truth' in entirely non-normative terms, and then it would aim to show that the process of taking one's experiences at face value satisfies the conditions that are given in the analysis.

I am not confident that any such reductive analysis of rationality is possible. The rationality of taking one's experiences at face value may simply be a bedrock normative truth, of which no such ulterior explanation can be given. So in clarifying the idea of a process that is a 'reasonable way of pursuing the truth', I shall not offer any such reductive analysis. Instead, I shall simply articulate some crucial features that all rational belief-forming processes must have, without attempting to ensure that these crucial features are picked out in strictly non-normative terms. Then I shall try to dispel the sense of puzzlement that surrounds the thesis that the process of taking one's experiences at face value is rational, by making it plausible that the process has these crucial features.

\subsection{ASSUMPTIONS ABOUT RATYONALITY}

In the discussion that follows, I shall rely on a number of assumptions about rationality. First, I shall assume that the view that epistemologists call 'internalism' is correct. That is, I shall assume that the processes through

Indeed, as we shall see later on, there are even some infallible belief-forming processes that seem not to count as reasonable ways to pursue the truth. So the fallibility of the process of taking expcriences at face value is not in fact essential to the fundamental problem that we are concerned with here. The fundamental problem is simply that it is not clear how any belief-forming process can be primitively rarional: focusing on fallible processes serves only to make this problem more intuitively vivid. which it is rational for a thinker to form beliefs at a given time $t$ are always determined purely by the facts that are in some way "internal" to the thinker's mind at $t$. Specifically, I shall assume that whether or not it is rational for a thinker to form beliefs by means of a given process at $t$ is entirely determined by the facts about what mental states the thinker has, what mental states the thinker lacks, and what mental abilities and capacities the thinker has, at $t^{6}$

If internalism about rationality is correct, the rationality of a beliefforming process must supervene purely on the thinker's mental states. The belief-forming process itself must be individuated purely in terms of the relations between the internal mental states involved; and the features of the process that make it a rational belief-forming process must consist purely of features that the process has in virtue of its role in the thinker's mind. Nothing that is external to the thinker's mind can be involved in making the process rational.

The most prominent rival to this internalist view of rationality is the 'reliabilist' view. According to the reliabilist view, whether or not a beliefforming process is rational depends entirely on whether it is a reliable way of arriving at the truth. ${ }^{7}$ I shall not attempt to defend internalism, or to criticize reliabilism, in this chapter. I shall simply assume for the sake of argument that internalism is true. This internalist assumption makes the problem that I am concerned with here significantly harder to solve. The reliabilist has an easy response to this problem. The reliabilist can just say, 'If, as a matter of fact, the process of taking one's experiences at face value is reliable, then it is a source of justified or rational beliefs; otherwise, it is not a source of justified or rational beliefs.' On the other hand, if the internalist view of rationality is correct, and reliabilism is incorrect, then this easy response is not available.

The second assumption about rationalicy that I shall rely on here is an assumption that I have already articulated - intuitively and metaphorically - by saying that the rational belief-forming processes must all be 'reasonable ways of pursuing the truth'. In other words, there must be some fundamental connection between rational belief-forming processes

"This sort of epistemological 'internalism' is attacked by Goldman (1999a) and defended by Conee and Feldman (2001). I have offered my own defence of internalism elowhere (Wedgwd cone as 1 explained there, in characterizing internalism, we need ro use a notion of 'mental sod 20026); cxcludes the so-called 'factive mental states' that play such a prominemt role in the epistemestogr of Williamson (2000).

7 For this reliabilist conception of justified belief, see Goldman (1979). 
and the truth. But exactly is it this fundamental connection to the truth that is a necessary feature of all rational belief-forming processes?

There are several possible connections between belief-forming processes and the truth that we could consider. First, some belief-forming processes themselves lead to the conclusion that these processes are reliable guides to the truth; engaging in these processes will itself lead us to believing in the reliability of these processes. As we might put it, these processes 'recommend themselves' as reliable or truth-conducive processes. Still, although this may be a necessary condition that rational belief-forming processes must meet, it cannot be a sufficient condition for the rationality of such processes - since many crazily irrarional processes might recommend themselves in this way.

Secondly, some belief-forming processes are in a sense infallible: if one genuinely forms a belief by means of this process, the belief is bound to be true. One example of such an infallible process is the process of forming the introspective belief that one could express by saying 'I am in pain' directly in response to the fact that one is in pain. But as we have seen, the process of forming beliefs by taking one's experiences at face value is an eminently fallible process, since one could form a belief by means of this process even if one was undetectably being deceived, so that the belief in question was not true at all. ${ }^{8}$

Thirdly, there are certain other processes that count as rational ways to form beliefs, but only because we have some process-independent way of forming a rational belief that the process is a reliable guide to the truth. For example, this seems to be the case with the processes in which we form beliefs on the basis of the use of measuring instruments. It is rational for me (in the absence of defeaters) to form a belief about the temperature of the air on the basis of reading a certain thermometer; but this is only because it is already rational - quite independently of the process of relying on this particular thermometer - for me to believe that the thermometer is reliable. However, I am assuming that this is not the case with the process of taking one's experiences at face value. If this is a rational process at all, it must be, as I put it, a primitively rational process.

Thus, it seems that none of these three connections to the truth can be a central part of what makes it rational to engage in the process of taking

${ }^{8}$ It may be correct to interpret much of the epistemology that was inspired by Descartes as motivated in part by the ambition to reconstruct as much of our knowledge of the world as possible purcly on the basis of rhese infallible bclicf-forming processes. I am assuming here that, contrary to the presuppositions that seem ro lie behind this tradition, fallible belief-forming processes can be perfectly rational. one's experiences at face value. Still, it seems that some such connection to the truth must be a central part of what makes it rational to engage in this process. We need to find a fourth connection to the truch.

\subsection{A CONNECTION TO THE 'TRUTH}

Given my internalist assumptions, any primitively rational belief-forming process is rational purely in vircue of the nature of the internal mental states involved. Thus, if a connection to che truth is part of what makes the process of taking experiences at face value a rational belief-forming process, this connection to the truth must also hold purely in virtue of the nature of the mental states involved. That is, whatever exactly this connection to the truth may be, it must be necessary that, given all the mental states involved in the process, the process has this connection with the truth. So, the process must have this connection to the truth in all possible worlds - even in 'demon worlds' where (because of the machinations of deceiving demons and the like) the process is not a reliable way to pursue the truth.

What sort of connection to the truth could this be? It must obviously be a weak connection to the truch, if the process has this connection with the truth even in 'demon worlds', where the process fails to be a reliable guide to the truth.

I propose that every primitively rational process has the following connection with the truth. The essential nature of the mental states that are involved in this process requires that any thinker who is capable of these mental states must have certain dispositions; and when all of these mental states arise from the manifestation of these essential dispositions, the process really is a reliable guide to the truth. With the process that I have called 'raking experiences at face value' the mental states involved are (a) an experience, and (b) the belief that one forms on the basis of the experience. So to see whether this process really has this sort of connection with the truth, we must investigate the essential nature of these mental states, to find out what are the dispositions that any thinker capable of these mental states must possess.

Of course, questions about the nature of experience are among the most controversial and disputed questions in the philosophy of mind. But most philosophers would agree that every experience has a content. This content is a representation of a possible state of affairs. When this state of affairs actually obtains, the experience will count as a veridical experience. For example, my current experience could represent the state of affairs of my 
holding my hands in front of my face; if I really am holding my hands in front of my face, then it counts as a veridical experience.

I tentatively suggest that it is an essential feature of sensory experiences that any subject who has experiences at all must have some disposition to have experiences that veridically represent certain aspects of her environment. This suggestion should not be read as implying that every such subject has a disposition for completely veridical experience - that is, a disposition to have experiences that do not represent any aspects of the environment non-veridically (let alone a disposition to have god-like experiences that represent all aspects of the environment veridically). Instead, this suggestion should be read as implying only that for every subject who has experiences at all, there are some aspects of the environment such that the subject has some disposition to have experiences that veridically represent those aspects of the environment. Presumably, one cannot have a disposition to have such veridical experiences by chance; so the relevant disposition must be a disposition to have an experience that veridically represents a certain state of affairs precisely in response to the fact that that state of affairs really does obtain. To fix ideas, we may assume that disposition ascriptions are equivalent to generalizations about what happens in 'normal conditions' - in other words, in conditions in which cetera are paria or 'other things are equal'. 9 More precisely, then, my suggestion is this: it may be a necessary truth that, for every subject of experience, there is a range of propositions such that for every proposition $p$ within that range, in normal conditions, the subject will respond to being in a situation in which $p$ is the case by having a sensory experience as of $p$ 's being the case. ${ }^{10}$

Why might this suggestion be true? It may be that this disposition to have partly veridical experiences is essential to explaining how experience has the specific content that it has. That is, the fact that a mental state is of the kind that would be involved in manifesting this disposition in response

9 It will obviously be a challenging task to give a detailed account of 'normal' conditions (i.e. conditions in which 'other things are equal'). Bur it seems that it is a task for metaphysics and the philosophy of science in general; it is not a special problem for the branch of epistemology that $I$ am focusing on here.

How can this disposition be ascribed to a subject of experience who is radically deceived, like the brain in a vat'? Perhaps the reason is that all subjects of experiences must have something like a brain that was, at least at some point during its existence, connected to a body in such a way that the subject was capable of perceiving and acting in a normal environment, and that brain must continue to function internally the same way as it did when it was connected to such a body. This may be enough to make it the case that the subject has this sort of disposition for veridical experiences (even though its current envatted condition now prevents this disposition from being manifested). But clearly the issue will require much further investigation. to being in a situation in which $p$ is the case may be an essential part of what makes this mental state count as a sensory experience as of $p$ 's being the case in the first place. ${ }^{.1}$

This suggestion does not imply that all of our sensory experiences arise from the operation of this disposition for veridical experiences. It only implies that we would not be capable of having experiences at all unless we had this disposition. Even if the manifestation of this disposition is blocked or inhibited by other factors (such as the machinations of an evil demon), the subject may still have this disposition. Admittedly, it may be impossible to have this disposition unless the disposition has at least somerimes been manifested. So it may be impossible to have experiences at all unless one has at some time in one's life actually manifested this disposition for veridical experiences. This would be a modest sort of 'anti-individualism' about sensory experiences. However, this sort of anti-individualism is still compatible with 'mid-life envatting': you might become a 'brain in a vat' only after your sensory experiences have been appropriately connected to the environment for long enough for them to be genuine conscious experiences with representational contents. So this sort of anti-individualism is still compatible with the possibility that you are now being radically and undetectably deceived.

Nonetheless, this sort of anti-individualism about experience does guarantee a certain sort of connection between the process of taking one's experiences at face value and the truth. Whenever one's experience does consist entirely in the manifestation of this essential disposition, then the content of the experience will be true. In short, there is a certain disposition, which is essential to having the capacity for sensory experiences at all, and when the process of taking one's experience at face value involves the manifestation of this disposition in this way, the process is reliable.

This sort of connection to the truth has the two features that we noted at the beginning of this section. It is clearly a weak connection to the truth, since a thinker can have such a disposition to have veridical experiences, even if the manifestation of this disposition is currently blocked or inhibited - for example, by the machinations of a deceiving demon. Nonetheless, this is still a connection that holds necessarily, in virtue of

"Compare Pcacncke's (2004:69) idca that experiences are 'instance-individutated with respect to certain of their contents'. Compare also Burge's (2003: 5ri) 'perceptual anti-individualism' - the idea that the "nature of a perceptual state, as marked by its representational content, is partly determined by relations berween the perceptual system ... and features of the environment that cause instances of its states and that states of the system representi'. 
the essential nature of the internal mental states that are involved in the process of taking experiences at face value. ${ }^{12}$

It may be that some such essential connection to the truth is a necessary part of what makes any belief-forming process primitively rational. Let us return to the metaphorical formulation that I used earlier, when I said that every rational belief-forming process must be a 'reasonable way of pursuing the truth'. To explore the significance of this metaphor, let us imagine that you were literally 'pursuing' the truth about a range of propositions; that is, for every proposition $p$ in this range, you actually intend to realize the goal of believing $p$ if and only if $p$ is true. Which processes would you choose to engage in as your means for pursuing this goal? In order to model our 'internalist' assumptions within the context of this metaphor suppose that you had to choose which belief-forming processes to engage in purely on the basis of the 'internal' features of this belief-forming process. In particular, how are you to choose which processes to treat as basicthat is, as the processes that you choose to engage in even in advance of any process-independent justification of those processes? It seems that one would have to choose processes that had some connection to the truth that held necessarily, purely in virtue of the nature or essence of the mental states that are involved in that process

One might wonder whether a thinker who was choosing which processes to treat as basic in this way would in fact always choose a set of processes that is infallible, in the sense that I discussed earlier. Why is it not the case that the only processes that it is reasonable for one to treat as basic in one's purstit of the truth are such infallible processes?

In fact, it seems that it would not be reasonable of the thinker to limit her belief-forming processes to these infallible processes. The goal is not just to avoid believing the proposition in question $p$ if $p$ is not true; it is also to believe $p$ if $p$ is true. To pursue this goal effectively, one needs processes that are not just reliably error-avoiding, but also reliably belief-yielding. ${ }^{\mathrm{I3}}$ While a set of belief-forming processes that includes only infallible processes could be reliably error-avoiding, it would not score well with respect to being belief-yielding. In particular, these infallible processes only seem capable of giving us beliefs about our own introspectible mental states and their logical consequences. But it seems plausible that we absolutely need to have beliefs

${ }^{12}$ Compare George Bealer's (2000: 7-10) 'modal reliabilism', according to which any 'basic source' of evidence must have a weak but necessary connection with the truth.

13 For a discussion of this point in slightly more detail, see some of my earlier work (Wedgwood 2002a) - although a more complete treatment of this issue would admittedly require much more investigation. about the contingent features of the external world if we are to be intelligent agents at all. No ser of cognitive processes could score well with respect to being belief-yielding unless it is at least possible for these processes to give us beliefs about the external world. So it seems that it would not in fact be a 'reasonable way for one to pursue the truth' to limit oneself to these infallible belief-forming processes. The only sort of connection to the truth that is necessary for all primitively national belief-forming processes is the weak sort of connection that I have described.

Still, it seems doubtful whether any such link to the truth can be a sufficient condition for the rationality of a belief-forming process. There seem to be many possible belief-forming processes that have some such necessary connection to the truth but are not intuitively rational. As BonJour (1980) in effect famously pointed out, the reliability of a process will not make the process rational if the configuration of mental states in the thinker's mind does nor justify the thinker in believing the process to be reliable.

To illustrate this point, consider the belief-forming process that consists in coming to believe a cerrain necessarily true proposition directly and immediately on the basis of simply considering the proposition. For example, this necessarily true proposition could be a highly non-obvious mathematical theorem; or it could be a necessary truth that can only be known empirically, such as 'Water $=\mathrm{H}_{2} \mathrm{O}$ '. Intuitively, this process is not rational even though it is necessarily reliable. It is only rational to form a belief in a non-obvious mathematical theorem on the basis of something like a proof (or on the basis of what one rationally believes to be reliable testimony); it is only rational to form a belief in the proposition that water is $\mathrm{H}_{2} \mathrm{O}$ on the basis of empirical evidence. It would not help to make this process rational if a whimsically manipulative neuroscientist had somehow 'wired you up' in such a way that this process was as psychologically basic for you as (say) the process of immediately coming to believe obvious logical truths like ' $\mathrm{I}=\mathrm{I}$ '. And if being wired up to form beliefs by means of this process by a whimsical neuroscientist cannot help to make it rational, I do not see how being wired up to do so by nature can either.

Thus, even though this connection between the process of taking one's experiences at face value and the truth is a necessary condition of the primitive rationality of the process, it is not a sufficient condition of its rationality. The fundamental problem seems to be that it is not enough if one just happens to form beliefs by means of a process that has this sort of connection to the truth. It is also necessary that on the relevant occasions, one forms beliefs by means of this process precisely because the process has this sort of connection to the truth. In this sense, it is only processes that 
one can engage in precisely because of their connection to the truth that can count as 'reasonable ways of pursuing the truch'. But we still do not yet understand how it is possible for one to form beliefs by means of a beliefforming process precisely because of the process's connection to the truth. In the last two sections of this chapter, I shall turn to another essential feature of primitively rational belief-forming processes, which seems to me to be capable of illuminating this idea in more detail

\section{A PRIORI PROCESSES}

Philosophers often distinguish between a priori justification and empirical justification. It is widely assumed that it is only beliefs that can have either $a$ priori or empirical justification. However, there is a natural generalization of this notion of a priori justification, so that it applies to belief-forming processes as well as to beliefs. In this section, I shall first explain what it would mean for the rationality of a belief-forming process to be a priori, and then I shall argue that the rationality of the primitively rational processes is $a$ priori in this way.

When a belief-forming process is rational, we can ask: What makes this process rational? In some cases, the rationality of the thinker's engaging in the process depends on the specific experiences that the thinker has had, or on the thinker's empirical background beliefs. In these cases, the rationality of the process is empirical. But in other cases, the rationality of the thinker's engaging in the process is independent of absolutely all the specific experiences and empirical beliefs that the thinker has had. In those cases, the rationality of the process is a priori.

If the rationality of a belief-forming process is a priori, and so independent of all of the thinker's specific experiences and empirical beliefs, what does make the process rational? In some special cases (for example, in the case of certain special mathematical proof techniques), it may be that the process is rational because the thinker has some independent a priori proof of the process's reliability. But this cannot be the case with the primitively rational processes - which we have defined to be processes the rationality of which is not due to the availability of any such independent justification. So it seems that if the rationality of a primitively rational process is a priori, then the process must already be rational for all thinkers who have the capacities that are necessary for engaging in the process. Such a process would be rational purely because the rationality of this process is in some way 'built into' the structure of those cognitive capacities themselves.
I am relying here on a broadly Kantian conception of the a priori. This is how Kant (1787: I) introduces the central question of the Critique of Pure Reason:

But even though all our cognition begins with experience, it does not follow that it all arises out of experience. For it may well be that even our empirical cognition is composed both out of what we receive through impressions and out of whar our own cognitive faculty (sensory impressions serving merely as the occasion) supplies out of itself.

Here Kant seems to be assuming that the a priori is what our cognitive faculties or capacities 'supply out of themselves'. Our cognitive capacities 'supply' a belief-forming process 'out of themselves', we may suppose, just in case any thinker who has those capacities either already has the ability to engage rationally in that process, or else is at least in a position to acquire that ability simply through exercising those capacities, without relying on any experiences or any other mental states that are not necessarily available to everyone who possesses those capacities.

This then is what it would be for the rationality of a basic belief-forming processes to be a priori: it would have to be a process that our cognitive capacities 'supply out of themselves' in this way. But why should we think that the primitively rational processes are a priori?

If we consider our favourite example of a primitively rational process the process of taking experience at face value - it seems plausible that the rationality of this process is a priori. It seems to be rational for every thinker to engage in this process - or at least for every thinker who has the capacities that are necessary for engaging in the process regardless of the specific experiences that they have had. Even if the thinker has the experience as of a demon's speaking to him out of the palm of his hand, mocking him with the claim that all his experiences are illusory, it would not become irrational for the thinker to engage in this process; since the process only involves forming beliefs on the basis of experience when special defeating considerations are absent, and in this case such special defeaters are present, it is simply impossible to form beliefs by means of the process in this case. Thus, the rationality of forming beliefs by taking experience at face value seems to be independent of all experiences and empirical beliefs whatsoever, and so to be a priori. As we might put it, this process cannot itself be read off from one's experiences, because it is precisely by means of this process that one reads anything off from one's experiences in the first place. 
This point can be generalized to all the primitively rational beliefforming processes. If the rationality of a belief-forming process were empirical rather than a priori, then the rationality of the process would depend on the specific experiences and empirical beliefs that the thinker has had: if the thinker had had sufficiently different experiences and empirical beliefs, the belief-forming process would not have been rational. But what possible collection of experiences and empirical beliefs could undermine the rationality of these basic belief-forming processes in this way? There presumably are some possible collections of experiences and empirical beliefs that would prevent it from being possible to form rational beliefs by means of these processes. But these collections of experiences and empirical beliefs will in effect counc as a defeating condition, and it seems plausible that each of these primitively rational processes is structured in such a way that it already involves sensitivity to the presence or absence of such defeating conditions: forming beliefs in the presence of these defeating conditions would not be an instance of this process at all. For this reason, it is just not true that when these defeating conditions are present, it becomes irrational to form beliefs by means of these processes. Thus, it seems that the rationality of these basic processes cannot be undermined by any possible collection of experiences and empirical beliefs whatsoever. In short, the rationality of these basic processes seems independent of absolutely all experiences and empirical beliefs - that is, it seems a priori.

If the rationality of a belief-forming process is a priori, the process musc be rational for all thinkers who possess the relevant cognitive capacities, regardless of the experiences and empirical beliefs that they have. Presumably, if it is rational for a thinker to engage in a belief-forming process, the thinker must either already possess the ability for rationally engaging in the process, or at least already be in a position to acquire this ability. So if a rational process is a priori, all thinkers who possess the relevant cognitive capacities must either already have the ability to engage rationally in the process, or at least be in a position to acquire an ability to engage rationally in the process (simply through exercising these capacities, without relying on any experiences or additional mental states that are not necessarily available to all thinkers who have those capacities).

However, if the process in question is a primitively rational process, it seems that all thinkers who have the relevant cognitive capacities must already have the ability to engage rationally in the process. The simplest explanation for this would be if the possession of these capacities essentially requires having some disposition to engage in the process. As I shall now propose, this is why these primitively rational processes count as a priori: a process is primitively rational if and only if there is some cognitive capacity of the relevant kind that essentially requires some disposition to engage in the process.

What is the 'relevant kind' of 'cognitive capacity'? One sort of capacity that is surely relevant is the possession of $a$ concept. For example, the possession of the concept 'green' is the capacity to have thoughts and attitudes involving this concept (that is, to have the sorts of thoughts and attitudes that are normally ascribed in English by means of attitudeascribing phrases in which the term 'green' appears in a hyperincensional context, such as 'thinking that grass is green', 'hoping for green pastures', and the like).

It would, however, be unwarranted to assume that our possession of concepts is the only sort of capaciry that is relevant here. It is equally important that we are capable of various sorts of attitudes, such as belief and intention. Moreover, in drawing up an inventory of the attitudes of which we are capable, it is importane not to overlook the full range and complexity of these atticudes. Belief itself comes in various degrees of belief and our thoughts can also be mere suppositions or wonderings racher than full-blown beliefs. Similarly, intentions seem prima facie different from other conative states, like aims and wishes and desires. So there are a great many more types of attitudes than just belief and intention.

In general, the capacities that are relevant here include: (i) one's possession of each of the various concepts that one possesses, and (ii) one's capacity for each of the various types of attitudes and mental states of which one is capable. My current proposal, then, is that what makes the primitively rational cognitive processes a priori is that they are precisely those processes that we must have some disposition to engage in if we are to possess these basic cognitive capacities. ${ }^{15}$

For example, consider the capacity of possessing the concept 'if' the capacity for thinking conditional propositions. Perhaps possessing this

${ }^{14}$ In this way, my proposal has a lor in common with that of several other philosophers - such a Boghossian (2002, 2003a), Peacocke (2004), and Pollock and Cruz (1999) - who have all maintained that many of the most fundamental belief-forming processes are in some way implicit in our possession of concepts. However, there are several differences between my proposal and theirs: th capacity that I am appealing that the possession of concepts is by no means the only sort of cognitive at as important as the possession of concepts.

the ad the rational belief-forning processes. According to this proposal, the primitively rational processes of the nature of these bonitive rational processes. 
capacity essentially involves a disposition to engage in the process of making inferences that have the form of modus ponens: "If $p$ then $q$, but $p$; hence $q$.' Perhaps, if you had absolutely no disposition of this sort, you could not even possess the concept 'if' at all. ${ }^{\mathrm{I}}$ In that case, according to the proposals that I have made here, the process of making modus ponens inferences would be a primitively rational process; and the way in which the process is built into our possession of the concept 'if' would explain why it counts as an a priori cognitive process.

Can this account of why the primitively rational processes count as $a$ priori also be applied to the process of taking one's experiences at face value? Suppose that it is the case that if one had no disposition to engage in this process, one would be incapable of forming beliefs in any contingent propositions about one's environment. Without such beliefs, one would not be capable of intelligent agency or practical reasoning at all, since all such practical reasoning has to start from some beliefs in contingent propositions about one's environment. Then there would be a particularly basic cognitive capacity - the capacity for intelligent agency and practical reasoning - that essentially requires some disposition to engage in the process of taking one's experiences at face value. If all this is right, then according to my proposals, the process of taking experiences at face value would also be an a priori primitively rational process.

Is it the case that unless one has some disposition to form beliefs by taking one's experiences at face value, one would be incapable of forming beliefs in contingent propositions about one's environment? It might seem that it is not the case. It may seem that there are other ways of forming such beliefs. For example, perhaps one could form beliefs about one's experiences by means of introspection, and then form beliefs about one's environment by means of an inference to the best explanation of one's experiences?

On reflection, it is not clear that it really would be possible to form beliefs in contingent propositions about one's environment in this alternative way if one had absolutely no disposition to take one's experiences at face value. In particular, it is not clear that one could form introspective beliefs about one's current experiences if one had no disposition to take one's experiences at face value. One clearly cannot form such introspective beliefs unless one can identify the conceptual content (or the 'conceptualized upshor', as I put

x6 The claim that possession of the concept 'if' requires a disposition to accept modtus ponens inferences has been cricicired by Williumson (2007: h. 4). I have tried to defend this chim a objections elsewhere (Wedgwood 2007 b). But for present purposes, I do not need actually to endorse objections elsewhere (Wedgwood 2007b). But for present purposes, I do not need actually to endorse that one must have some disposition to engage in if one is to possess that concepr. it in section 9.I) of those experiences. But it is not clear that one's experiences would have any conceptual content at all, unless one were at least disposed to form beliefs directly on the basis of one's experiences. (Indeed, on some views of the matter, the conceptual content of an experience precisely consists in the proposition that the thinker is disposed to come to believe in direct response to that experience.) So we may tentatively conclude that a disposition to engage in the process of taking one's experience at face value is necessary if one is to be capable of having beliefs in contingent propositions about one's environment - and so of being an intelligent agent at all. So a disposition to engage in this process is a necessary condition of this basic cognitive capacity. If that is right, then according to my proposal, this process would count as an a priori primitively rational process. ${ }^{17}$

In this section, I have proposed an explanation of why the primitively rational processes count as a priori - they are processes that our basic cognitive capacities 'supply out of themselves' in this way - and I have provided some reasons for thinking that we can give the very same explanation of why the process of taking our sensory experience at face value is a priori. But what does this proposal have to do with the problem that we confronted at the end of the previous section? How does this proposal help us to see how it is possible for us to engage in this process precisely because of its connection with the truth?

\subsection{A SOLUTION TO THE PROBLEM}

In the previous section, I proposed that the primitively rational cognitive processes are precisely those that we must have some disposition to engage in if we are to possess certain basic cognitive capacities (such as the capacity of possessing a particular concept, or the capacity for a certain type of atticude). However, there is an obvious objection that some philosophers might be tempted to raise against this proposal. Why could it not be the case that one of these cognitive capacities requires a disposition to engage in a thoroughly irrational belief-forming process?

In section 9.3, I proposed that the primitively rational belief-forming processes must at least have some essential connection to the truth (even if it is only a weak connection). So taken together my proposals imply

A full defence of this proposal would of course have to make it plausible that all of the primitively rational processes - including relinace on memory induction, and iuference to the besc primitively among others - are proccseses that our basic cognitive opaciies 'supply out of themsexelves' in this way Unforenatcly I cannot attempt to carry out this task here (aldhough I hope to do so on another occasion). 
that possessing these basic cognirive capacities cannot require having the disposition to engage in any belief-forming process unless that process has at least some such connection to the truth. But why could it not be the case that one of these basic capacities requires a disposition to engage in a misleading process that altogether lacks any such connection to the truth?

In fact, however, it seems, at least to me, to be most doubtful whether these capacities could essentially involve a disposition for such irrational or misleading processes. How can these capacities - our possession of concepts and our capacities for all of the various types of artitude - essentially require a disposition to engage in a belief-forming process that has no such connection with the truth? These capacities are cognitive powers, not cognitive foibles or liabilities. ${ }^{18}$ Possessing the concept 'if' may essentially involve a disposition to accept certain truth-preserving inferences, such as modus ponens; but it is surely perfectly possible to possess this concept without having any disposition to accept fallacious inferences, such as 'affirming the consequent' or 'denying the antecedent'. In general, it seems plausible that these capacities cannot essentially require a disposition to engage in a belief-forming process unless that process has some appropriate connection with the truth.

We can dramatize this point by considering the idea of a perfectly rational being. It seems plausible to me that every concept that we possess could also be possessed by this perfectly rational being. (For example, this perfectly rational being would have to make use of these concepts in order to ascribe mental states to us and to diagnose the errors and confusions that mar our thinking.) I am also inclined to accept the following thesis: for every concept, there is a specific cognitive process that one must have some disposition to engage in if one is to possess the concept. But of course the perfectly rational being has no disposition to engage in any irrational processes. So the processes that are essentially built into these concepts cannot be irrational processes; they must be rational processes instead. Unless a belief-forming process has some essential connection to the truth, it cannot be a rational process. So the processes that are in this way built 18 This point is in effect the central idea of my argument for the normativity of the intentional
(Wedgwood 2007a: 169 ), which was originally suggested to me by teflecting on Gareth Evans's (1982: 33r) insistence that understanding a linguistic expression is a species of knowledge and so cannot be based on false belief: :Truth is seamless: there can be no trurh which it requires acceprance of a falsehood to appreciare.' Some philosophers will object by claiming that rhere are 'essentially defective conceprs' - concepts possession of which essentially requires irrational dispositions of some kind. However, as I have argued elsewhere (Wedgwood 2007b), there are in fact compelling reasons to deny the existence of such 'defective concepts'. into our possession of concepts must be rational processes that have an essential connection to the truth of this kind.

At the end of section 9.3, I argued that the mere existence of an essential connection between a belief-forming process and the truth was not enough to make the process rational; it is also necessary that one should be able to engage in this process precisely because of its connection with the truth. In the case of the non-primitively or derivatively rational belief-forming processes, one can engage in them because one has independent justification for believing them to have an appropriate connection with the truth that is, because there is some other rational process that can lead one to the belief that these derivatively rational belief-forming processes have an appropriate connection to the truth. But in the case of the primitively rational processes, one can engage in these processes simply because one must have a disposition to do so, purely in virtue of possessing certain concepts or being capable of certain types of attitude. Since it is necessary for any disposition that is built into one's possession of a concept or one's capacity for some type of attitude in this way to have some such connection to the truth, one can also engage in these processes precisely because of their connection to the truth - even if one does not engage in these processes because one has any process-independent justification for believing them to have such a connection to the truth.

According to my proposals, then, these processes are built into the very nature of our capacities for the concepts that we possess, or for the types of attitude that we are capable of. This explains why they are a priori, as I explained in the previous section; and it also explains why it is possible for us to engage in these processes precisely because of their connection with the truth. In this way, my proposals explain why these processes have these crucial features that any primitively rational process would have to have. ${ }^{19}$

If I am also right that we must have a disposition to engage in the process of taking our experiences at face value if we are to have the capacities of intelligent agency and practical reasoning, then we have all the materials that we need to solve the problem about how this basic belief-forming process can be rational. Just like all other primitively rational processes, this process is built into the very nature of our fundamental cognitive capacities, and is therefore an a priori process, which it is possible for us

xy This is a slightly different account from the one that I proposed in earlier work (Wedgwood 1999). "There I claimed, in effect, that the belicf-forming processes that are built into our concepts and capacities for arfitude-types are primitively rational because they form the 'only non-arbierary to make chat claim on the basis of the arguments that I offered at that time. 
to engage in precisely because of its essential connection with the truth. This should help to dispel any sense of puzzlement that we might have had about how it can be that it is a genuinely rational belief-forming process. ${ }^{20}$

${ }^{20}$ Earlier versions of this chapter were presenced ar a conference at the University of Edinburgh, at a conference that was organized by New York University in Florence, and (in German) at the University of Göttingen. I am gratcful to all those audiences, to my commentators at those conferences - Alan Millar in Edinburgh, and Ram Nera and Stephen Schiffer in Florence - and also to Cian Dorr, Lizzie Fricker, Maria Lasonen-Aarnio, Joshua Schechter, Nicholas Shea, David Wallace, Timothy Williamson, and an anonymous referec, for helpful cornments. The first draft of this paper was completed while $I$ was a Visiting Fellow at the Institute for Advanced Study at the

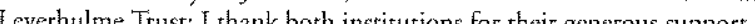

CHAPTER IO

\section{What does it take to "have" a reason?}

Mark Schroeder

If I believe, for no good reason, that $\mathrm{P}$ and I infer (correctly) from this that Q, I don't think we want to say that I "have" $P$ as evidence for $Q$. Only things that I believe (or could believe) rationally, or perhaps, with justification, count as part of the evidence that I have. It seems to me that this is a good reason to include an epistemic acceprability constraint on cvidence possessed. ${ }^{\mathrm{I}}$

It is a truism that adopting an unjustified belief does not put you in a better evidential position with respect to believing its consequences. This truism has led many philosophers to assume that there must, at a minimum, be a justification condition (or perhaps a knowledge condition) on what it takes to count as having evidence. This is the best (or only) possible explanation of the truism, these philosophers have believed. This chapter explores an alternative explanation for the truism. According to the alternative explanation, unjustified beliefs do not put you in a better evidential position with respect to believing their consequences because evidence you have in virtue of having an unjustified belief is guaranteed to be defeated. Since lack of justification for a belief guarantees its defeat, I will suggest, we don't need to postulate a special justification condition (much less a knowledge condition) on what it takes to count as having evidence.

Why is this important? Because the assumption that there must be a justification condition (or a knowledge condition) on what it takes to count as having evidence places a high bar on what it takes to have evidence such a high bar that it is difficult to see how it could be met in the case of basic, perceptually justified beliefs. As a result, the high bar set by this condition plays a fundamental role, I will claim, in central features of a core dialectic from the epistemology of basic perceptual belief. Given the degree to which this dialectic is shaped by the assumption of the high bar on what it takes to have evidence, I believe that it is worth taking seriously

Feldman (1988b: 227). 